\title{
The role of specific experiences in childhood and youth in the development of body integrity identity disorder (BIID)
}

\author{
Catharina Obernolte ${ }^{1}$, Thomas Schnell ${ }^{2}$, Erich Kasten ${ }^{3}$ \\ ${ }^{1}$ Dept. of Psychology, Friedrich-Schiller-University, Fürstengraben 1, 07743 Jena, Germany \\ ${ }^{2}$ Dept. of Clinical Psychology, Medical School Hamburg, University of Applied Sciences, Am Kaiserkai 1, D-20457 Hamburg, Germany \\ ${ }^{3}$ Dept. of Neuropsychology, Medical School Hamburg, University of Applied Sciences, Am Kaiserkai 1, D-20457 Hamburg, Germany

\section{Email address:} \\ c.obernolte@hotmail.de(C. Obernolte), thomas.schnell@medicalschool_hamburg.de (T. Schnell), EriKasten@aol.com (E. Kasten)
}

\section{To cite this article:}

Catharina Obernolte, Thomas Schnell, Erich Kasten. The Role of Specific Experiences in Childhood and Youth in the Development of Body Integrity Identity Disorder (BIID). American Journal of Applied Psychology. Vol. 4, No. 1, 2015, pp. 1-8.

doi: 10.11648/j.ajap.20150401.11

\begin{abstract}
Task: BIID (Body Integrity Identity Disorder) is an intense feeling of discrepancy between a real intact body and the subjective mental image of a disabled body (e.g. amputation, palsy). The disturbance exists since late childhood or early adolescence and often results in the desire for a surgery. The cause is still unknown but may lie in early developmental phases. Until now, childhood experiences have not been subject of systematic psychological research of BIID. Methods: On the basis of specific hypotheses we investigated differences between a BIID-group $(n=36)$ and an age and gender parallelized group ( $\mathrm{n}=36)$. BIID sufferers vs. control subjects were examined for the following characteristics: quality and quantity of experiences with mental and physical disease, experiences with secondary profit from illness, maladaptive education (emotional neglect, overprotection) and a general admiration for handicapped people in their youth. Results: On the basis of the findings of the present study, it can be assumed, that BIID afflicted persons had experienced no considerable maladaptive education from their parents, neither in the direction of physical abuse nor as overprotective control. On the other hand we found significant differences in specific childhood experiences, particularly with regard to quantity and quality of emotional experience with disability; e.g. participants from our BIID-group reported significantly more disabled people in their former environment than participants from our control group $(M B I I D=3.69 \pm 0.75, M$ control $=1.47 \pm 0.41, p=0.004)$. Moreover we found significant discrepancies according to positive or negative associations towards disability in childhood ( $M$ BIID $=5.44 \pm 0.31, M$ control $=3.88 \pm 0.29, p<0.01)$. We assume those specific experiences with handicapped people in the surrounding of BIID-patients as to be a trigger for early conflicts with the appearance of their own body and an intense feeling that a disabled body fits better to their mental body image. Future investigation should focus on the validation of those cognitions, e.g. through a comparison of BIID-affected people who shared the same social environment in childhood (e.g. siblings).
\end{abstract}

Keywords: BIID, Body Integrity Identity Disorder, Body Incongruence Disorder, Apotemnophilia, Xenomelia,

Amputee Identity Disorder, Childhood Experiences, Disabled People, Desire for Amputation, Metal Body Image

\section{Introduction}

BIID ("Body Integrity Identity Disorder", also termed as "Amputee Identity Disorder", "Body incongruence Disorder" or "Xenomelia"), is described as an intense feeling of a discrepancy between a real intact body and a subjective mental image of a disabled body (e.g. amputation, palsy). Consensually, BIID is associated with the existence of a strong desire for a severe (physical) infirmity [3, 4]. The afflicted person believes to be "complete" only if realizing the amputation of a limb. Solely sufferers who successfully achieved the desired operation reported healing from BIID [12].

With regard to the causes of BIID, Kasten (2009) suggested a multi-causal influence of (1) a psychological, (2) a neurological and (3) a sexual component [5]. From a neurological point of view dysfunctions in the upper right parietal lobe are argued as a possible cause of the BIID symptoms [3, 7]. Such dysfunctions can cause e.g. hemineglect, the alien limb syndrome or asomatognosia. The feeling of alienness in case of some parts of the body depicts a crucial symptom BIID affected people share. Noting that the desire for a disability in BIID afflicted people usually refers to 
the contralateral left leg constitutes evidence for a neurological basis in terms of a dysfunction of the right parietal lobe. In contrast to this neurological explanation, Kasten (2012) and Kasten \& Stirn (2009) described cases, in which the choice for amputation of a specific leg based on rational reasons, such as driving a car $[9,10]$.

The affected people perceive a very precisely defined line where the amputation stump should be. However, this line corresponds more to the naive concept of a one-legged person, rather than the sensory regions of the spinal nerves [8-10]. Nonetheless, examinations could not detected extensive neurological lesions in the brain as e.g. in hemineglect in BIID Studies by McGeoch et al. (2009) could demonstrate no major damage, but probably minimal deficits existing in the right parietal lobe [11].

Merely a part of the BIID affected person report a sexual component. They feel sexually aroused by the sight of leg- or arm-stumps. At this point, we assume overlaps with disorders of sexual preference, in which people feel sexually attracted by people with missing limbs (Acrotomophilia, Mancophilia, Amelotism, deformation fetishism, devotees).

Michael First (2005) pointed to the notable similarities between Body Integrity Identity Disorder (BIID) and Gender Identity Disorder (GID, transgender) [6]. Both groups suffer from feelings being in the wrong body. In BIID as well as in GID the disturbance initiates in childhood and partially involves erotic feelings with regard to the desired body in both cases.

Most patients indicate the characteristic symptoms of their BIID desire already being existed in childhood or adolescence. They often remember specific key events with disabled people [7-10]. Until now, systematic investigations about the childhood of BIID afflicted people are rare. Our study aimed for the examination of childhood related issues in association with infirmity. Hence, we detected whether BIID-sufferers have had a higher number of experiences with disabled people in their childhood, if they have had secondary gains from being ill in their youth and if they were victims of maladaptive parenting behavior (emotional neglect, overprotection). Furthermore, we asked for a general admiration for "otherness".

As a possible cause of BIID Stirn et al. (2010) defined a genetic based pre-pubertal imprinting connected with identification of an admired disability on one's own body scheme [14]. We hypothesized a reinforcement of quantitative and qualitative experiences with disabled people in the early childhood. This could have led to a change in the body image, resulting in the development of an "Amputee Identity". Concerning this, we expected to exhibit significant differences of experiences in childhood and youth between BIID sufferers and control subjects.

\section{Methods}

BIID is a very rare disturbance, which affected individuals do not realize until adolescence. Therefore, it is impossible to implement a longitudinal study beginning in early childhood.
The only possibility is to create a retrospective questionnaire about specific experiences in early periods of life of BIID affected people and to contrast their answers to those of a parallelized group of unaffected people.

For this purpose, we designed a questionnaire with 59 items participants should rate on a scale between 0 and 100 (unidirectional) or between -50 and +50 (bidirectional) in steps of 10 with verbal markers on the poles. For statistical analysis these scales were transformed into 1 to 11 scales (see Table 1).

Table 1. Transformation of the original 1 to 100 or -50 to +50 scales to a 1 to 11 scale.

\begin{tabular}{|c|c|c|c|c|c|c|c|c|c|c|c|}
\hline Scale & mar & king & & & & & & & & & \\
\hline $\begin{array}{l}\text { Original } \\
\text { unidirectional }\end{array}$ & 0 & 10 & 20 & 30 & 40 & 50 & 60 & 70 & 80 & 90 & 100 \\
\hline $\begin{array}{l}\text { Original } \\
\text { bidirectional }\end{array}$ & -50 & -40 & -30 & -20 & -10 & 0 & +10 & +20 & +30 & +40 & +50 \\
\hline Transformed & 1 & 2 & 3 & 4 & 5 & 6 & 7 & 8 & 9 & 10 & 11 \\
\hline
\end{tabular}

We parallelized the control group of our study by age and sex and designed the used questionnaires with the assistance of the internet-program "SoSci-Survey"; links to this internet page were provided to the people via email or were published in BIID internet forums. After setting a survey period, the questionnaires were accessible online. The data were automatically sent to the personal account of the authors. Statistical analysis was performed with the program PASW-Statistics-18. Due to the small sample size and the ordinal-level of our data the results were analyzed by using non-parametric significance test for two independent samples (Mann-Whitney U test). We tested on a 5\% significance level. In case of nominal data, the frequencies were calculated, and a chi-square test was performed. Some items were combined into a total score. Descriptive statistics depict mean values \pm standard error.

\section{Results}

We analyzed the responses of 36 BIID affected individuals (4 female, 32 male), followed by the detection of a control group parallelized by age and gender. The mean age of the total sample was $46.99 \pm 1.37$ years (BIID M: $47.06 \pm 2.00$ control M: $46.92 \pm 1.90$.). $13.9 \%$ of BIID sufferers and $2.8 \%$ of the control subjects were homosexual. Due to Years of education, we found the following percentage distributions for each category: category 9-13 years of education: $16.7 \%$ (BIID) vs. $19.4 \%$ (control); $14-18$ years: $58.3 \%$ (BIID) vs. $38.9 \%$ (control); 19-23 years: $22.2 \%$ (BIID) vs. $41.7 \%$ (control).

\subsection{Results for hypothesis H1a}

In childhood and adolescence BIID sufferers have had severe physical illnesses more frequently than non-sufferers.

We found no significant differences between the two groups $\left(\chi^{2}(1,0 ; \mathrm{df}=1, \mathrm{~N}=72)=0.000\right)$. At this point, we asked for specific kinds of illnesses, but no accumulations were found. Likewise, with regard to the duration of the reported diseases (in weeks), no significant accumulations were found for the 
BIID group in contrast to the controls $(\mathrm{U}=2.0, \mathrm{Z}=-1.414, \mathrm{p}=$ 0.16 , n.s.). In addition, there was no significant difference between the groups regarding to the period, in which a person suffered from of a severe physical illness. Concerning the extent of experienced physical limitations due to the specified illness no significant differences were found $(\mathrm{U}=11.000, \mathrm{Z}=$ $-0.325, \mathrm{p}=0.84$, n.s.), too.

\subsection{Results for hypothesis $\mathrm{H} 1 \mathrm{~b}$}

In childhood and adolescence BIID sufferers have had severe mental disturbances more frequently than non-sufferers.

For the prevalence of severe mental disturbances in childhood, no significant differences between the BIID sufferers and control subjects were found $\left(\chi^{2}(1,0 ; 1, N=72)\right.$ $=0.000)$. The same applies to the extent of psychological distress, which evinced no significant mean differences ( $U=$ $38.000, Z=-0.222, p=0.82$, n.s.). Similarly, the number of psychological therapies in childhood and youth showed no significant differences between BIID and control group $\left(\chi^{2}\right.$ $(1,0 ; 1, \mathrm{~N}=72)=0.000)$.



Figure 1. Differences between BIID and control group (mean $\pm S E$ ) for the item "How many physically disabled people or people with aids such as orthotics / prosthetics / wheelchair / crutches etc. were in your childhood / youth in your surroundings. The item was answered in numbers $(B I I D=3.10 \pm 0.62$, control $=1.89 \pm 0.56)$.

\subsection{Results for hypothesis H1c}

In childhood and youth BIID sufferers have had more experience with severe physical disability than the controls.

Considering this hypothesis we ascertained significant differences between the BIID sufferers and the control group $(\mathrm{U}=399.000, \mathrm{Z}=-2.885, \mathrm{p}=0.004 * *$, see Fig. 1).

An analysis of variant kinds of disabilities ("amputation", "paralysis", "blindness", "deafness ", "other") revealed significant mean differences in the number of persons with specific handicaps in the surrounding of the respondents in his/her childhood and youth $(U=338.000, Z=-3.577$, $\mathrm{p}<0.01^{* *}$, see Fig. 2) . Focusing on the disability-categories separately, analysis revealed significant differences between the two groups, particularly for "amputees" in the surrounding (amputation: $U=396.000, Z=-3.322, p<0.01 * *$; paralysis: $U=$ 590.500, $Z=-0.797, p=0.43$; blindness: $U=628.500, Z=$ $-0.351, p=0.73$; deafness: $U=591.000, Z=-1.118, p=0.30$; others: $U=570.000, Z=-1.116, p=0.30$; see Fig. 3 ).

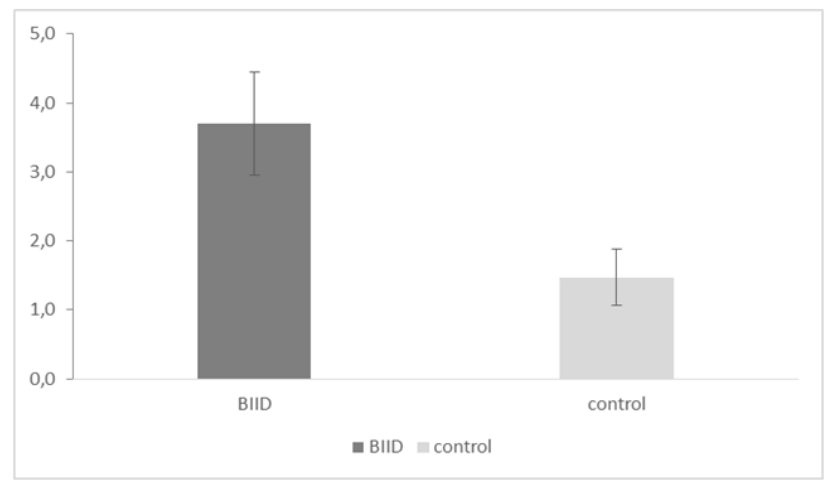

Figure 2. Differences between BIID and control group (mean \pm SE) for the item: "Please estimate the number of people in your environment in your childhood and teenage years, with the following physical disabilities..." The item was answered in numbers $(B I I D=3.70 \pm 0.75$, control $=1.47 \pm 0.41)$.

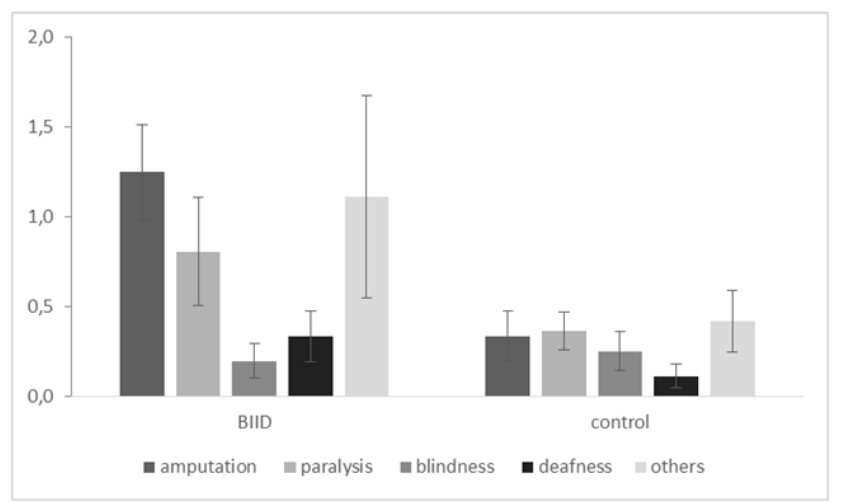

Figure 3. Differences between BIID and control group (mean $\pm S E$ ) for the item: "Specific number of disabled person in the surrounding of respondents in childhood age (BIID-amputation $=1.25 \pm 0.27$, control-amputation $=0.33 \pm 0.14 ; \quad B I I D$-paralysis $=0.81 \pm 0.30$, control-paralysis $=0.36 \pm 0.11 ; \quad$ BIID-blindness $=0.19 \quad \pm \quad 0.10$, control-blindness $=0.25 \pm 0,11 ; \quad$ BIID-deafness $=0.33 \pm 0.14$, control-deafness $=0.11 \pm 0.07$, BIID-other $=1.11 \pm 0.57$, control-other $=0.42$ \pm 0.20 ).

With the next question, we determined the quality of the relationship to a physically disabled person in childhood. We could not demonstrate significant differences between the groups $(U=276,000, Z=-0.924, p=0.36$, n.s. $)$. In contrast, the evaluation of the question how the participants rated disability in their childhood on a continuum between the poles "very negative" and "very positive", revealed significant differences between BIID- and non-BIID-participants $(\mathrm{U}=348.500, \mathrm{Z}=$ -3.385, p<0.01**; see Fig. 4).

A specific analysis of varied kinds of handicaps exhibited significant differences between the BIID and the control group in view of the relationship to other people for "palsy" and "amputation" (palsy: $U=320.500, Z=-3.743, p<0.01 * *$; amputation: $U=140.000, Z=-5.814, p<0.01 * *$; see Fig. 5). Apart from that, for "blindness" ( $U=605.000, Z=-0.500$, $\mathrm{p}=0.62$, n.s.), "deafness" ( $\mathrm{U}=636,000, \mathrm{Z}=-0.139, \mathrm{p}=0.90$, n.s.) and "mental retardation" $(U=566.500, Z=-0.951, p=$ 0.34 , n.s.) no significant differences between the two groups were indicated. 


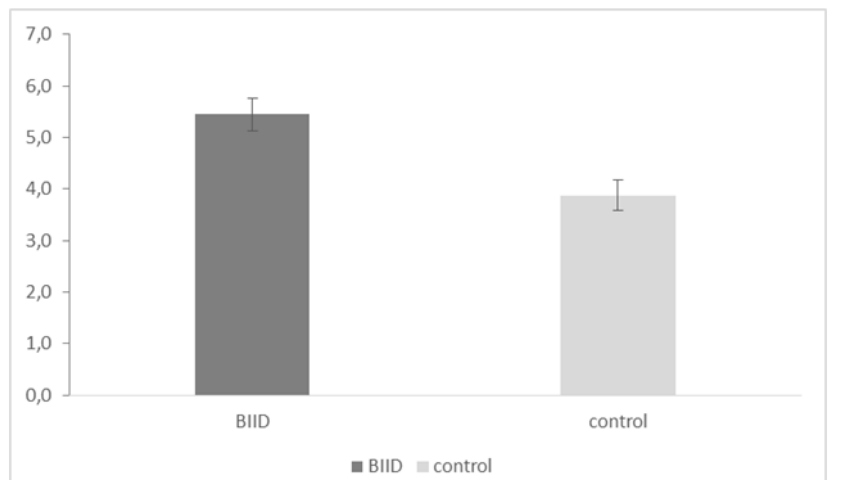

Figure 4. Differences between BIID and control group (mean $\pm S E$ ) for the item: "How strongly have you associated in your childhood disabilities with negative / positive aspects" $(B I I D=5.44 \pm 0.31$, control $=3.88 \pm 0.29)$. In this case the BIID-mean of 5.44 resembles a negative rating of -10 , the control-mean of 3.88 resembles an even more negative rating of -30 on a coded scale from -50 to +50 , as we mentioned in our method section above.

\subsection{Results for hypothesis $\mathrm{H} 2$}

BIID sufferers have been rewarded in their childhood / youth with secondary gain from illness than non-affected people.

The investigation of illness-based "secondary gain" was made with several items. One aspect we tested was the preservation of attention from the surrounding for "otherness". The original unidirectional scale was constructed from 0 (= not more attention) to 100 (= much more attention), which was, as explained above, transformed into a scale from 1 to 11 . We found for BIID an average result of $\mathrm{M}=4.14 \pm 0.56$ and for the controls $\mathrm{M}=3.06 \pm 0.54$; the difference was not significant, but showed a trend $(U=494.000, Z=-1.847$, $\mathrm{p}=0.065$, n.s.).

For the aspect of the "feeling of love by family members when ill" on a bidirectional scale from -50 (less love) to +50 (much more love) no significant differences between the BIID and the control group could be pointed out $(\mathrm{BIID}=5.33 \pm 0.29$, control $=4.0 \pm 0.30, \mathrm{U}=629.000, \mathrm{Z}=-0.215, \mathrm{p}=0.83$,n.s.). $\mathrm{A}$ category-specific analysis of "mother", "father" and "grandparents", could not depict significant differences between the two groups neither (BIID-mother $\mathrm{M}=8.67 \pm 0.30$; control-mother $\mathrm{M}=8.39 \pm 0.37, \quad \mathrm{U}=621.000, \quad \mathrm{Z}=-0.309$, $\mathrm{p}=0.76$, n.s.; $\quad$ BIID-father $\quad \mathrm{M}=7.44 \pm 0.33$, control-father $\mathrm{M}=7.47 \pm 0.36, \quad \mathrm{U}=613.000, \quad \mathrm{Z}=-0.402$, $\mathrm{p}=0.69$, n.s.; $\quad$ BIID-grandparents $\mathrm{M}=7.64 \pm 0.33$, control-grandparents $\mathrm{M}=7.33 \pm 0.39, \mathrm{U}=633.000, \mathrm{Z}=-0.174$, $\mathrm{p}=0.86$, n.s.).

Significant differences failed out for the extent of attention and affection for ill or handicapped people, which the participants have noticed as children on a unidirectional scale (BIID $\mathrm{M}=3.78 \pm 0.50$, control $\mathrm{M}=2.81 \pm 0.36 ; \mathrm{U}=543,000$, $\mathrm{Z}=-1.250, \mathrm{p}=0.21$, n.s.).

A further issue was, whether participants remembered a feeling as a child about siblings receiving more love from their parents and grandparents. There were only $n=26$ BIID and $\mathrm{n}=29$ control subjects with brothers or sisters. The originally used unidirectional scale from 0 (= siblings don't got more love) to 100 (=siblings got very much more love), was transformed to a 1 to 11 scale. We could exhibit a significant difference for the category "mother" (BIID-mother $\mathrm{M}=2.77 \pm 0.50$, control-mother $\mathrm{M}=1.90 \pm 0.45, \mathrm{U}=272.500$, $\mathrm{Z}=-2.154, \mathrm{p}=0.03^{*}$ ), but not for other relatives (BIID-father $\mathrm{M}=1.77 \pm 0.24$, control-father $\mathrm{M}=1.90 \pm 0.37, \mathrm{U}=354.000$, $\mathrm{Z}=-0,474, \mathrm{p}=0.64$, n.s.; BIID-grandparents $\mathrm{M}=1.58 \pm 0.26$, control-grandparents $\mathrm{M}=1.90 \pm 0.43, \mathrm{U}=362.500, \mathrm{Z}=-0.329$, $\mathrm{p}=0.74$, n.s.).

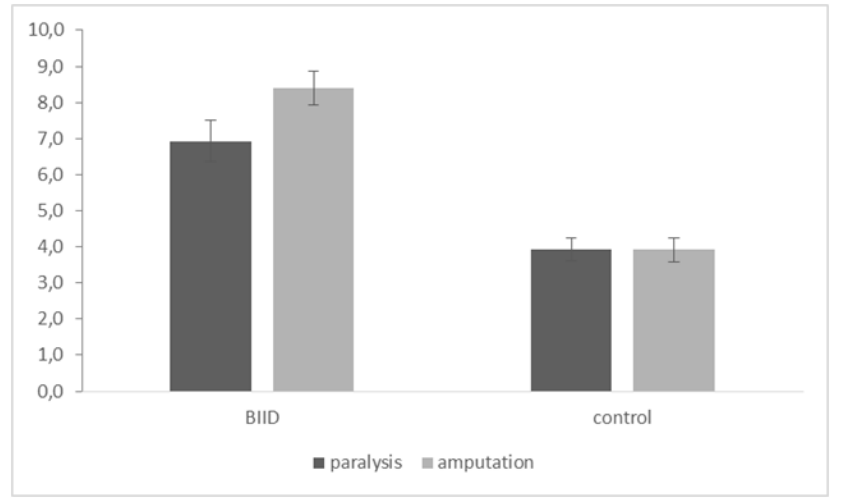

Figure 5. Differences between BIID and control group (mean \pm SE) for the variables "paralysis" and "amputation" of the item "How much do you have associated to your childhood disabilities with negative /positive aspects." (BIID-paralysis $=6.92 \pm 0.57$, control-paralysis $=3.92 \pm 0.32$; BIID-amputation $=8.39 \pm 0.47$, control-amputation $=3.92 \pm 0.33)$. In the case of paralysis the BIID-mean of 6.92 resembles a neutral to less positive rating of between 0 to +10 ; the control-mean of 3.92 resembles a negative rating of between -30 to -20 on a coded scale from -50 to +50 . In the case of amputation the BIID-mean of 8.39 resembles a positive rating of about +20 , the control-mean of 3.92 resembles a negative rating of between -30 to -20 on the same scale.

\subsection{Results for hypothesis $\mathrm{H} 3 a$}

BIID sufferers have experienced in childhood more maladaptive parental behavior in the form of emotional neglect than the controls.

We investigated this hypothesis with several items. Primarily, we asked for feelings of hate or love received from the parents. As explained above, the originally used bidirectional scale from -50 (hated) to +50 (loved) was transformed into a 1 to 11 scale, i.e. numbers below 6 tend to the endpoint "hated" and numbers higher than 6 to the endpoint "loved". The results displayed no significant differences between the BIID- and the control group (BIID-mother $\mathrm{M}=9.28 \pm 0.37$, control-mother $\mathrm{M}=9.58 \pm 0.34$, $\mathrm{U}=586.500, \quad \mathrm{Z}=-0.730, \quad \mathrm{p}=0.47, \quad$ n.s.; $\quad$ BIID-father $\mathrm{M}=9.03 \pm 0.32$, control-father $\mathrm{M}=9.25 \pm 0.33$, $\mathrm{U}=591.500$, $\mathrm{Z}=-0.655, \mathrm{p}=0.51$, n.s.).

Another aspect related to the hypothesis of emotional neglect was the extent of affection received by other people on a unidirectional scale between "not at all" and "very much". Between the groups we found no significant differences (BIID $\mathrm{M}=6.64 \pm 0.47, \quad$ control $\mathrm{M}=7.25 \pm 0.43, \quad \mathrm{U}=569.000$, $\mathrm{Z}=-0.897, \mathrm{p}=0.37$, n.s.).

Two following questions asked on two unidirectional scales for punishment in the case of laziness or inadequate efforts 
and benefits for high efforts, respectively. The differences between the groups proved to be not significant (BIID-benefit $\mathrm{M}=8.17 \pm 0.44$, control-benefit $\mathrm{M}=8.17 \pm 0.40, \mathrm{U}=620.500$, $\mathrm{Z}=-0.315, \mathrm{p}=0.75$, n.s.; BIID-punishment $\mathrm{M}=4.28 \pm 0.54$, control-punishment $\mathrm{M}=2.97 \pm 0.36, \mathrm{U}=508.000, \mathrm{Z}=-1.613$, $\mathrm{p}=0.11$, n.s.).

Further on, we asked for self-confidence in the childhood on a bidirectional scale between "I felt nothing worth" and "I felt very valuable". Again, we exposed no significant differences between the groups (BIID $\mathrm{M}=8.69 \pm 0.37$, control $\mathrm{M}=8.86 \pm 0.38, \mathrm{U}=602.5000, \mathrm{Z}=-0.523, \mathrm{p}=0.60$. n.s. $)$.

For some items with sufficient homogeneity, we calculated a sum score as a basis for further statistical analysis. The unidirectional items "How much affection have your parents given you in childhood/adolescence?" and "How much have you felt safe with your parents?" had a sufficient Cronbach's Alpha coefficient of $\alpha=0.83$. We detected no significant difference between the two groups (BIID $\mathrm{M}=8.06 \pm 0.38$, control $\mathrm{M}=8.60 \pm 0.42, \mathrm{U}=542.000, \mathrm{Z}=-1.199, \mathrm{p}=0.23$, n.s.).

The sum score of the following items "Did your parents encourage your interests and hobbies?", "Have your parents made private enterprises together with you?" and "Have your parents promoted your interests, when mutual activities were planned?" had a Cronbach's $\alpha=0.87$, but exhibited no significant differences between BIID and controls (BIID $\mathrm{M}=7.48 \pm 0.45, \quad$ controls $\quad \mathrm{M}=7.44 \pm 0.43, \quad \mathrm{U}=636.500$, $\mathrm{Z}=-0.130, \mathrm{p}=0.90$, n.s.).

For the items "Have you felt rejected as a child or teenager?", "Have you wanted as a child and teenager to get more attention and affection?" and "Were you as child / adolescent punished from your parents for not being like your parents had wished (e.g. false interests or to be unsportsmanlike etc.)?" Cronbach's Alpha was $\alpha=0.83$. No significant differences were displayed (BIID $\mathrm{M}=2.92 \pm 0.28$, control $\mathrm{M}=2.75 \pm 0.31, \mathrm{U}=569.500, \mathrm{Z}=-0.885, \mathrm{p}=0.38$ ).

The next cluster of items included the two unidirectional questions: "Have you been left alone with your problems as a child or teenager?" and "Were your parents attentive when you don't felt good (e.g. because you were sad)?" Cronbach's Alpha was $\alpha=0.75$. The group differences let to non-significant results (BIID $\mathrm{M}=5.60 \pm 0.24$, control $\mathrm{M}=5.56 \pm 0.16, \mathrm{U}=266.500, \mathrm{Z}=-0.291, \mathrm{p}=0.31$, n.s. $)$.

Besides, there were no significant results in the analysis of the following cluster of questions: "Have you got slaps in your childhood/adolescence?", " Have you been punished in your childhood/adolescence with blows (beatings)?" and "Have you experienced sexual abuse in your childhood on your own body". Each item had to be rated on a unidirectional scale. Cronbach's Alpha was $\alpha=0.70$. (BIID $M=1.70 \pm 0.14$, control $\mathrm{M}=1.73 \pm 0.14, \mathrm{U}=619.000, \mathrm{Z}=-0.328, \mathrm{p}=0.74, \mathrm{n} . \mathrm{s})$.

\subsection{Results for Hypothesis $\mathrm{H} 3 \mathrm{~b}$}

BIID sufferers have experienced in their childhood/adolescence more maladaptive parental behavior in the form of overprotection than the controls.

In this aspect of our examination about maladaptive parental behavior, we examined various aspects of overprotective behavior. Merely the aspect of "requirement for perfection by the parents" revealed significant differences in experience with overprotective parents $(U=365.000$, $\mathrm{Z}=-3.226, \mathrm{p}<0.01$, see Fig. 6).

The results of the assessment of overprotection by parents in childhood or adolescent on a unidirectional scale did not differ significantly between the two groups (BIID $\mathrm{M}=4.03 \pm 0.46, \quad$ control $\quad \mathrm{M}=4.03 \pm 0.48, \quad \mathrm{U}=644,500$, $\mathrm{Z}=-0.040, \mathrm{p}=0.97$, n.s.).

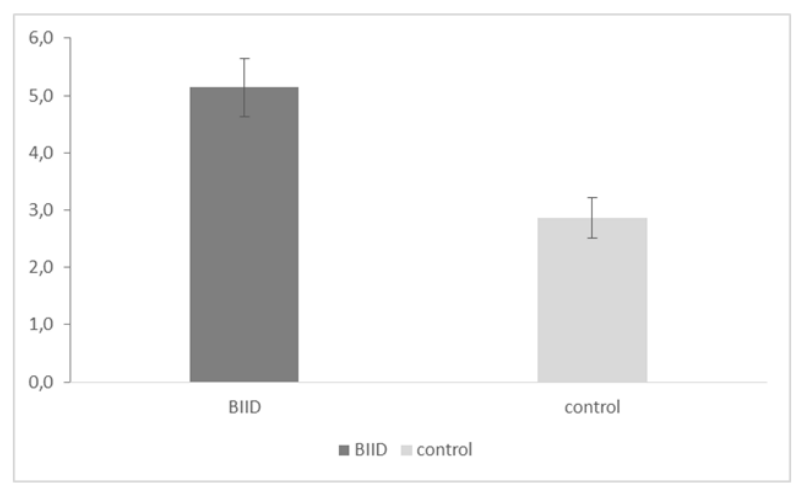

Figure 6. Differences between BIID and control group (mean $\pm S E$ ) for the item: "Did your parents always claimed to you to be absolutely perfect in everything what you did as a child / teenager?" on a unidirectional scale. $(B I I D=5.14 \pm 0.51$, control $=2.86 \pm 0.35)$. Ratings had to be made on a scale from not at all $0(1)$ - 10(2) - 20(3) - 30(4) - 40(5) - 50(6) - 60(7) - 70(8) - 80(9) - 90(9) - very often 100(10).

Furthermore, the differences for the unidirectional question for an independence promoting education by parents approved to be non-significant (BIID $\mathrm{M}=7.86 \pm 0.40$, control $\mathrm{M}=8.28 \pm 0.42, \quad \mathrm{U}=572.000, \quad \mathrm{Z}=-0.869, \quad \mathrm{p}=0.39, \quad$ n.s. $)$. Incidentally, we provided a cluster of additional unidirectional items: "My interaction with other children and young people was determined and controlled by my parents", "Were you controlled pedantic in your childhood and youth by your parents?", "Have your parents always corrected everything you have done in childhood/youth?", "Have your parents always patronized you as child / adolescent when designing your spare time?". Cronbach's Alpha for this pool of questions yielded $\alpha=0.76$. The overall sum score-analysis showed up to be non-significant in this group of questions (BIID M=4.03 \pm 0.46 , control $\mathrm{M}=4.03 \pm 0.48, \mathrm{U}=644,500, \mathrm{Z}=-0.040$, $\mathrm{p}=0.97$., n.s.). Nonetheless, the specific analysis of the item according to the aspect of pedantic control by our participants parents possessed significant mean-differences (BIID $\mathrm{M}=3.56 \pm 0.32$, control $\mathrm{M}=2.75 \pm 0.36 ; \mathrm{U}=472.000$, $\mathrm{Z}=-2.020, \mathrm{p}=0.04)$.

\subsection{Results for Hypothesis $\mathrm{H} 4$}

BIID afflicted person admire people with eye-catching attributes more than controls.

The analysis of the question "Which feeling do you receive when you look at individuals with the following attributes: severe overweight, foreign skin color, amputation, down-syndrome, growth-restriction, port-wine stains, heavily tattooed and pierced" brought out significant differences 
between the two confronting groups, respecting the sum scores of all ratings for each attribute. The ratings had to be made on a bidirectional scale with the endpoints "repulsive" $(-50)$ to "fascinating" $(+50)$, again coded as a scale from 1 to 11 as mentioned above $(U=426.500, Z=-2.499, p=0.01 * *$, see Figure 7).

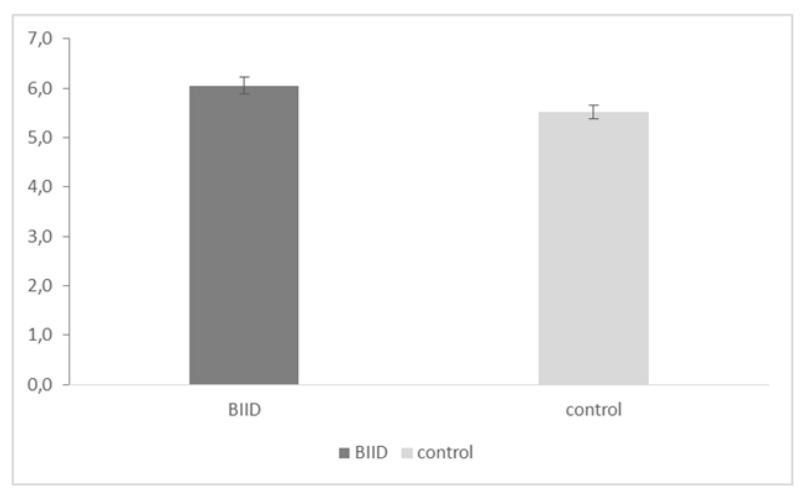

Figure 7. Differences between BIID and control group (mean \pm SE) for the item: "How do you estimate the sight of people with the following attributes: obese people, people with colored skin, amputees, Down syndrome, people of small stature, people with a port wine stain and heavily tattooed and pierced people. Assessed on a bidirectional rating scale between the endpoints "repulsive" $(-50)(1)-(-40)(2)-(-30)(3)-(-20)(4)-(-10)(5)-(0)(6)-(+10)(7)$ - $(+20)(8)-(+30)(9)-(+40)(10)$ - "fascinating" (+50)(11) (BIID $M=6.05 \pm 0.17$; control $M=5.52 \pm 0.14)$.

Regarding to the separate categories, only "amputation" led to a significant difference between BIID and controls (see Tab.2)

Table 2. Difference between BIID- and non-BIID affected people with regard to admiration of people with eye-catching attributes on a 11 step scale between repulsive and fascinating.

\begin{tabular}{llll}
\hline Attribute & BIID & Controls & Significance \\
\hline Amputation & $9.56 \pm 0.30$ & $6.06 \pm 0.98$ & $\mathrm{p}<0.01 * *$ \\
Severe overweight & $9.56 \pm 0.30$ & $3.44 \pm 0.25$ & $\mathrm{p}=0.79, \mathrm{n} . \mathrm{s}$ \\
Foreign skin color & $6.58 \pm 0.20$ & $6.67 \pm 0.24$ & $\mathrm{p}=0.91, \mathrm{n} . \mathrm{s}$ \\
Down-syndrome & $5.64 \pm 0.29$ & $5.92 \pm 0.22$ & $\mathrm{p}=0.65, \mathrm{n} . \mathrm{s}$ \\
Growth-restriction & $6.08 \pm 0.33$ & $6.56 \pm 0.25$ & $\mathrm{p}=0.25, \mathrm{n} . \mathrm{s}$ \\
Port-wine-strains & $5.39 \pm 0.24$ & $5.69 \pm 0.21$ & $\mathrm{p}=0.51, \mathrm{n} . \mathrm{s}$ \\
Heavily tattooed/pierced & $5.33 \pm 0.47$ & $4.28 \pm 0.49$ & $\mathrm{p}=0.66, \mathrm{n} . \mathrm{s}$ \\
\hline
\end{tabular}

\section{Discussion}

The aim of this study was to determine, whether BIID sufferers had common typical experiences in their childhood and youth in contrast to not afflicted control subjects. The results should promote the acquirement of knowledge about psychological factors in the development of BIID-phenomenon.

We supposed that BIID afflicted individuals had suffered more from physical illness or mental disturbances in their childhood than others. However, results of the testing of these first two hypotheses (H1a and $\mathrm{H} 1 \mathrm{~b}$ ) revealed no significant differences between BIID and controls. As far as the interviewees remembered, they did not have more diseases in their youth. Especially according to our assumption that in childhood illnesses of a BIID-desire corresponding body part, such as the right leg, causes the development of desire for amputation of a limb, we found no statistical confirmation. Likewise, early mental disturbances were no common factor for the BIID group.

In comparison to the previous hypotheses, our results displayed a highly significant difference in hypothesis H1c: For the period of childhood and youth, BIID sufferers remembered more experiences with severe physical ill and disabled people in their social surrounding than non-sufferers. Notable, they remembered contact to amputees and people with palsy, but not to other disabled person (blindness, deafness, mental retardation).

In this aspect, our findings confirm theoretical assumptions of Stirn et al. (2010) who defined a pre-pubertal genetic based imprinting connected with identification of an admired disability on one's own body scheme [14]. This is supported by the fact that the body scheme and the body self-image underlie learning experiences. The body scheme is constantly changing depending e.g. from gaining or losing weight and the body self- image is, among other aspects, composed of beliefs, assumptions, illusions and interpretations that arise in the social confrontation [2].

Unclear remains, whether they really have had more contact to handicapped people or if they only remember these contacts better than the controls. Even in childhood, the disability has had a special meaning for them. Moreover, we cannot state a definite answer whether BIID sufferers might have made more positive or negative emotional experiences with disabled person in their childhood. Although the results for positive or negative association with disability in childhood were significant, an unambiguous statement, whether this effect is due to the influence of a desire to be disabled would not be valid. We therefore assume that "disability" is a more salient stimulus for BIID sufferers than for the non-affected controls. A continued intern, mental discussion about the desire for disability could be the basis for better memories and a positive estimation of the early experiences with disabled person.

Hypothesis H2 - BIID sufferers were rewarded in their childhood more frequently with secondary gain from illness than non-sufferers could not be approved. As well, a positive influence of a reward for any kind of "otherness" in childhood and youth as a cause for the wish for amputation was not affirmed, there was only a trend for a group difference between BIID and controls. However, secondary gain for illness seems not to be the main reason for the BIID desire.

The notion behind hypothesis H3a that BIID afflicted person have had experienced more maladaptive parental behavior in the form of emotional neglect than non-sufferers was not corroborated. None of the item-related analyses revealed significant differences between the two groups. In this context, Stirn et al. (2010) highlighted evidences that parents did not sufficiently perceive the needs and wishes of their children. Typically, they found a busy, emotionally distant father and a rather "more present" but also "passively experienced" mother [14]. In our study we only found decent differences between the educational stile of the mother and father and no group differences between BIID and controls. 
Likewise the hypothesis H3b that BIID sufferers have experienced more overprotection, showed no clear significant differences. Only for "requirement for perfection" and "pedantic control" significant differences were found, but the results were in the lower third of the dimension for both groups, which, despite the significant difference, contradicts the assumption of overprotection of parents in the BIID group. Nevertheless, the results of the item analysis of hypothesis $\mathrm{H} 3 \mathrm{a}$ and H3b hint at abnormalities in parents' behavior of BIID sufferers, which should be followed up in future research.

Hypothesis H4 claimed that BIID sufferers had already admired as children people with eye-catching attributes. In our data this could only be proved for amputation and palsy, not for other kinds of otherness or handicaps.

Based on our trials it can be assumed, that BIID afflicted persons had experienced no considerable maladaptive education from their parents. Neither in the direction of physical abuse nor as overprotective control. We detected nearly no significant difference between the BIID and the control group. With regard to another aspect of investigation, the BIID-affected group remembered having made more intense experiences with disablement than non-sufferers. It is conceivable that these experiences have led to a change in the own body scheme, hence the change of body self-image and the development of an "Amputee Identity" [13].

Our findings led us to the arising of the theory, that according to a key-lock-principle - already in the childhood the BIID afflicted person react in a more positive way on the first sight of a handicapped person. Whereas an unaffected child reacts with negative feelings (e.g. he or she feels sorry for this person) the later BIID-person has positive emotions as e.g. excitement and a strong feeling for that the own body should likewise appear in this way. Until now, there are no other studies about childhood-related experiences in BIID-people.

\section{Conclusion}

Childhood experiences have not been subject of systematic psychological research in BIID context, yet. Therefore, our study proposed to examine childhood related issues in association with infirmity and experiences with disabled individuals, respectively.

We assume specific experiences with handicapped people in the surrounding of BIID-patients as to be a trigger for early conflicts with the appearance of their own body and the intense feeling of a disabled body fitting better to one's mental body image.

Findings about our assumption that BIID afflicted individuals had suffered more from physical illness or mental disturbances in their childhood than others, resulted in non-significant differences between the BIID-group and controls.

Asking about quantitative experiences with disabled people in childhood/youth, BIID sufferers remembered more experiences with severe physical ill and disabled people in their social surrounding than non-sufferers. Notably, they remembered contact to amputees and people with palsy, but not to other disabled person (blindness, deafness, mental retardation). Likewise, the analysis due to qualitative aspects (positive/ negative valence) with disablitiy itself in childhood demonstrated significant results.

In Addition to this, inferences about secondary gain for illness underlying the genesis of the crucial BIID desire would not be valid based on our data.

According to maladaptive parental behaviours (emotional neglect, overprotection) as an aspect of our investigation, no common experiences could be detected in the BIID sample. Our study emerged merely decent but non-significant differences between the educational stile of the mother and father and no group differences between the BIID group and controls.

The assumption that BIID sufferers had already admired people with eye-catching attributes as a child could only be proved for amputation and palsy, not for other kinds of otherness or handicaps.

Future investigation should focus on the validation of the retrospectively reported experiences, e.g. due to a comparison with utterances of persons who shared the same social environment in childhood (e.g. siblings). We suggest that following studies should try to confirm our findings about quantitative and qualitative differences in experience with disability in early youth of BIID afflicted individuals.

\section{Acknowledgements}

The authors thank all of the participants of this study for their contribution and support. The ambitious and confiding participation of the BIID afflicted person and not afflicted controls contributed fundamentally to the knowledge gained. Special thanks to Monika and Richard who conducted helpful annotations during the generation of the questionnaire.

\section{References}

[1] Bayne, T., Levy, N. (2005). Amputees By Choice: Body Integrity Identity Disorder and the Ethics of Amputation. Journal of Applied Philosophy, 22(1), 75-86.

[2] Bechstein, M. (2012). Körperkonzept - Körperschema Körperbild. Abgerufen am 18.07.2013 von http://www.mbechstein.de/reader_pm/theorie_themen/06_koer perkonzept.pdf

[3] Blanke, O., Morgenthaler, F. D., Brugger, P., Overney, L. S. (2009). Preliminary evidence for a fronto-parietal dysfunction in able-bodied participants with a desire for limp amputation. Journal of Neuropsychology, 3, 181-200.

[4] Blom, R. M., Hennekam, R. C., Denys, D. (2012). Body Integrity Identity Disorder. PLoS ONE 7(4): e34702. doi:10.1371/journal.pone.0034702

[5] Brang, D., McGeoch, P. D., Ramachandran, V. S. (2008). Apotemnophilia: a neurological disorder. Cognitive Neuroscience And Neuropsychology, 19(13), 1305-1306. 
[6] First, M. B. (2005). Desire for amputation of a limb: paraphilia, psychosis, or a new type of identity disorder [Abstract]. Psychological Medicine, 35, pp 919-928. doi:10.1017/S0033291704003320.

[7] Kasten, E. \& Spithaler, F. Body Integrity Identity Disorder: Personality Profiles and Investigation of Motives. In: A. Stirn, A. Thiel \&. Oddo (Eds.) Body Integrity Identity Disorder. Pabst Science Pubishers, 2009; 20-40.

[8] Kasten, E. (2009). Body Integrity Identity Disorder (BIID): Befragung von Betroffenen und Erklärungsansätze. Fortschritte Neurologischer Psychiatrie, 77, 16-24.

[9] Kasten, E. (2012) Body Integrity Identity Disorder Körperidentität durch erwünschte Behinderung. Psychiatrie und Psychotherapie up to date. 2012; 6(3): 165-177.

[10] Kasten, E., Stirn, A. (2009). Body Integrity Identity Disorder (BIID) wechselnder Amputationswunsch vom linken auf das rechte Bein. Zeitschrift für Psychiatrie, Psychologie und Psychotherapie, 57(1), 55-61.
[11] McGeoch, P. D., Brang, D., Song, T., Lee, R. R., Huang, M., Ramachandran, V. S. (2009). Apotemnophilia - the Neurological Basis of a 'Psychological' Disorder. Nature Precedings : hdl:10101/npre.2009.2954.1 : Posted 17 Mar 2009

[12] Noll, S. (2010). Integrity Identity Disorder (BIID)- Kann eine Amputation/Operation Betroffenen langfristig helfen? Bachelorarbeit, Stiftung Universität Hildesheim, FB Erziehungs- und Sozialwissenschaften, Institut für Psychologie.

[13] Obernolte, C. (2013). Ursachenforschung: Gibt es Gemeinsamkeiten in der Kindheit und Jugend von BIID-Betroffenen? - Bachelorarbeit, MSH Medical School Hamburg - University of Applied Sciences and Medical University, Hamburg, Germany.

[14] Stirn, A., Thiel, A., Oddo, S. (2010). Body Integrity Identity Disorder (BIID)- Störungsbild, Diagnostik, Therapieansätze. Basel: Beltz Verlag. 